days of rapid progress: it has been produced in less than seven months.

Prof. Lehninger begins with a succinct account of the historical development of the subject. He then deals with the structural aspects, and this is followed, in several chapters, by a discussion of the oxidative processes (citric acid cycle, fatty acid oxidation and ketone body oxidation and formation, the properties of the electron transport chain and the mechanism of oxidative phosphorylation, including the energetics of mitochondrial metabolism and the control and integration of the various metabolic processes). Other chapters deal with the active transport of ions by mitochondria and with energy-coupled changes of volume and structure. One chapter is devoted to the ultra-structure in which the author discusses the information relevant to bridging the gap between electron microscope and chemical investigations of the basic molecules, or molecule assemblies, which have to be fitted into the structure.

Particularly stimulating is the final chapter on the bio-genesis of mitochondria, a subject on which informa. tion is still very scanty. Various hypotheses are discussed and include the de novo synthesis of mitochondria from sub-microscopic precursors present in the cytoplasm, the formation from other membranous structures in the cell, and the growth and division of pre-existing mitochondria. Mitochondria certainly have the capacity to synthesize some of their protein from amino-acids. Other mitochondrial components are synthesized extramitochondrially and taken up 'ready made' by the growing (or adapting) mitochondria. But the source of the mitochondrial matrix - the outer cell membrane, the endoplasmatic reticulum, the nuclear membrane, the nucleolus and Golgi apparatus have all been suspected-is still unknown.

The book integrates in a happy way the different kinds of mitochondrial investigations-biochemical, physiological and structural. No doubt it will find many friends among students at all lovels.

HANS KREBS

\section{TRAINING THE INDUSTRIAL WORKER}

Training within the Organization

A Study of Company Policy and Procedures for the Systematic Training of Operators and Supervisors. By David King. Pp. xxii +274 . (London: Tavistock Publications (1959), Ltd., 1964.) $38 s$.

$\mathrm{N}^{\mathrm{o}}$

OW that the State has taken over responsibility for the development of industrial training and has empowered Industrial Training Boards to extract a levy from companies for training purposes, the attention being directed by industry and commerce to training has shown a noticeable increase. Attention, however, is not enough and many industrial managements are finding that the training required of them is much more than the sit-by-him variety. The help of specialists is being increasingly sought and, where they can show a practical approach to methods of training which lead to demonstrable improvements in workers' efficiency, managements are more than ready to accept their recommendations

Training within the Organization aims to provide a systematic approach to the training of operators and supervisors which, so far as it goes, could be most useful to those concerned with the training of operators. King first presents a case-study of a company in Norway which was faced with the need to improve the performance of women employed in garment making. He describes how the elements of jobs were differentiated by analytical methods, how a training sequence and programme were built up, how an instructor was selected and trained, and how the trained novitiates were introduced to the more austere conditions on the factory floor. In a neighbouring factory a similar approach to the training of supervisors led to the setting-up of self-governing working groups.

In the second part of the book the author examines the process of learning and shows how it should be used in training. The third section establishes the place of operator training in the company organization and, in the fourth section, detailed procedures in the training of operators are explained. The author also includes a chapter indicating how the effectiveness of training can be reviewed.

All in all, the case for the systematic training of operators in manual skills is well presented and the book will meet only with the criticism that it contains little that is new and has not been more succinctly presented by others elsewhere. If Mr. King had ventured outside the now familiar training schemes for sewing machinists, garment folders or stocking linkers, his book would have gained wider support, but the narrowness of his approach detracts from the appeal of the book. The inference throughout the whole work is that all that is needed in training operators is improvement in dexterity and that the systematic approach to the inculcation of skills is the universal panacea. The cognitive aspects of an operator's job are almost entirely ignored, and in those jobs where knowledge is at least as important as systematic training to develop manual skills, dexterity could be but a small part of the overall training required. In a chemical plant, for example, or in oil refineries, the operators need not only to be highly skilled manually but also to be well aware of what is taking place in pots and vessels and when and how to read instruments so that manual skills can be properly used. Nor will an approach which is not difficult to introduce on inexpensive equipment like sewing machines offer much comfort to managers faced with the problem of training operators for capital equipment like rolling mills, or for jobs that can only be done by operators working in teams, particularly where complete now teams are seldom required.

Mr. King's exhaustive approach to the development and administration of company training schemes also leaves much to be desired. Rather than detailed procedures, managers and supervisors would welcome guidance about what are, for them, complicated differences between City and Guilds and National Certificate Courses; when and where to recommend operative, craftsman, Intermediate Certificate and full technological courses; differentiation between Higher National Certificates and Higher National Diplomas and what endorsements mean to Section ' $C$ ' examinations of the professional institutions. To suggest that operator training schemes can be developed without reference to accompanying educational courses is to take an unrealistic specialist view which implies that we have not progressed far from the concept of the employ. ment of 'hands' in industry.

The attention directed to the training of supervisors is so scanty that it is difficult to understand why it was included.

T. H. Hawkins

\section{ECONOMICS OF EDUCATION}

The Control of Education

By John Vaizey. Pp. 263. (London: Faber and Faber, 1963.) $30 s$.

THE Control of Education, the publishers claim, tells I us "about education-its value, its cost, its control". In fact, it tells us little about these things but a great deal about Mr. Vaizey's opinions concerning them.

Mr. Vaizey has collected together a number of talks and papers which he has given at various times covering a variety of topics such as "Education and Economic Development"; "Manpower"; "A Policy for Higher Education"; "The Status of Teachers". There has been 